\title{
Development and Pilot Validation of an Instrument Assessing Sensorimotor Skills for Percutaneous Gastral Puncture
}

\author{
Monika Engelke $^{\mathrm{a}}$ Karl Ernst Grund ${ }^{\mathrm{b}}$ Dieter Schilling ${ }^{c} \quad$ Ulrike Beilenhoff ${ }^{\mathrm{d}}$ \\ Ferdinand Stebner $^{e}$ Christiane Kugler ${ }^{f}$ \\ ${ }^{a}$ Department of Nursing Science, University Witten/Herdecke, Witten, Germany; ${ }^{b}$ Center of Medical Research, \\ University Clinics Tübingen, Tübingen, Germany; ${ }^{\mathrm{C}}$ Medical Clinic II, Diakonissen Hospital Mannheim, \\ Mannheim, Germany; ${ }^{d}$ ESGENA Scientific Secretary, DEGEA President, Ulm, Germany; ${ }^{e}$ Department of Research \\ on Learning and Instruction/Institute of Educational Science, Ruhr University Bochum, Bochum, Germany; \\ ${ }^{f}$ Institute of Nursing Science, Faculty of Medicine, Albert-Ludwigs-University Freiburg, Freiburg, Germany
}

\section{Keywords}

Sensorimotor skills · Instrument development · Content validation · Assessment instrument · AS-PEG

\begin{abstract}
Introduction: The acquisition of sensorimotor skills, socalled "technical skills", plays an essential part in the professional and continuing educational training of medical and nursing staff. Facilities turn to simulator training to promote the safe and accurate performance of endoscopic examinations. Thus, this study aimed to develop and pilot-test a corresponding assessment instrument to monitor necessary sensorimotor or "technical" skills of the examiner for a safe percutaneous endoscopic gastrostomy (AS-PEG). Materials and Methods: Instrument development and pilot validation involved four stages: identification of potential items and initial draft of the AS-PEG; expert panel with 11 experts (content validity index [CVI] calculated); empirical validation using a quasi-experimental intervention on simulators; revision of the pilot AS-PEG taking expert assessment, and empirical testing into consideration. Results: The initial instrument yielded 13 categories and 44 items describing the PEG procedure. Experts rated 30 out of 44 items (68\%) extremely or very important for the safety of the puncture of the stomach. Initial item-CVIs ranged from 0.00 to 1.00 ; scaleCVI was 0.61 . Twenty-four trainees (7 physicians, 17 nurses)
\end{abstract}

participated in the pilot simulation study. On average, 8:25 min were required for PEG placement (min-max 5:59-13:38 $\min , \mathrm{SD}=1: 43$ ). The revised AS-PEG version was reduced to 14 items with a range of the item CVI from 0.8 to 1.0 , and a scale-CVI of 0.90 . Conclusion: The AS-PEG instrument facilitates the evaluation of sensorimotor skills during percutaneous gastric puncture procedures within the context of PEG placement, across professions and without relating to the number of procedures previously performed. The instrument is economical and shows satisfying content validity.

(c) 2020 S. Karger AG, Basel

\section{Introduction}

The acquisition of sensorimotor skills, so-called "technical skills," plays an essential part in the professional and continuing educational training of medical and nursing staff $[1,2]$.

In the past, the acquisition of sensorimotor skills required for endoscopic procedures was often based on the number of procedures performed on patients [3, 4], whereas simulator training and standardized assessments of trainees' abilities to perform the procedure safely were rarely used $[5,6]$. Recently, simulators have been increasingly used to train sensorimotor skills with subsequent evaluation by suitable assessment instruments [7-9]. 
Instruments used for the assessment of sensorimotor skills are designed to facilitate an objective evaluation while being reliable and valid [10]. Koch [11] and Ekkelenkamp et al. [12] provide an overview of various aspects of the training and the assessment of sensorimotor skills required in gastrointestinal endoscopy. However, none of the studies explicitly focused on the puncture of the stomach within the context of percutaneous endoscopic gastrostomy.

In Sedlack's "Mayo Colonoscopy Skills Assessment Tool (MCSAT)," content validity is regarded as the starting point for the evidence of validity $[5,13]$. Content validity can be defined as "the degree to which an instrument has an appropriate sample of items for the construct being measured" [14], and can be ensured when adhering to the developmental stages of (1) domain identification, (2) item generation and (3) instrument construction, in addition to selection of and consultation with experts [15]. In clinical medicine, it is important to ensure that assessment instruments are evidence based and allow transparent scoring $[16,17]$.

This study aimed to develop an assessment instrument for monitoring the sensorimotor skills required for PEG placement (AS-PEG). A quasi-experimental intervention study on simulators was conducted with the focus on training physicians' and nurses' sensorimotor skills required for the puncture of the stomach within the context of PEG placement. Performance of physicians in the beginning stages of specialty training and of nurses having completed the specialist post-basic nursing education in endoscopy was recorded and assessed [18].

\section{Materials and Methods}

According to Waltz et al. [19], a criterion-referenced approach was chosen to determine to what extent participants' sensorimotor skills met the standard described in the literature. This paper follows the "recommendations for reporting the results of studies of instrument and scale development, and testing [20]."

\section{Development of the Assessment Instrument and Content}

Validation

Content validation was divided into two stages based on current expert recommendations [21]: (1) development stage, and (2) judgement quantification stage. These two stages were succeeded by an empirical testing of the preliminary version of the AS-PEG in a pilot study with a quasi-experimental design, stage 3 . Stage 4 comprised a revision of the instrument (Fig. 1).

\section{Assessment Instrument for Percutaneous Endoscopic Gastrostomy (AS-PEG)}

Stage 1: Development Stage

The identification of potentially relevant items was achieved by a comprehensive literature review. Relevant databases were searched, including publications since 1980, the year during which PEG placement was first described [22]. Taking indications for

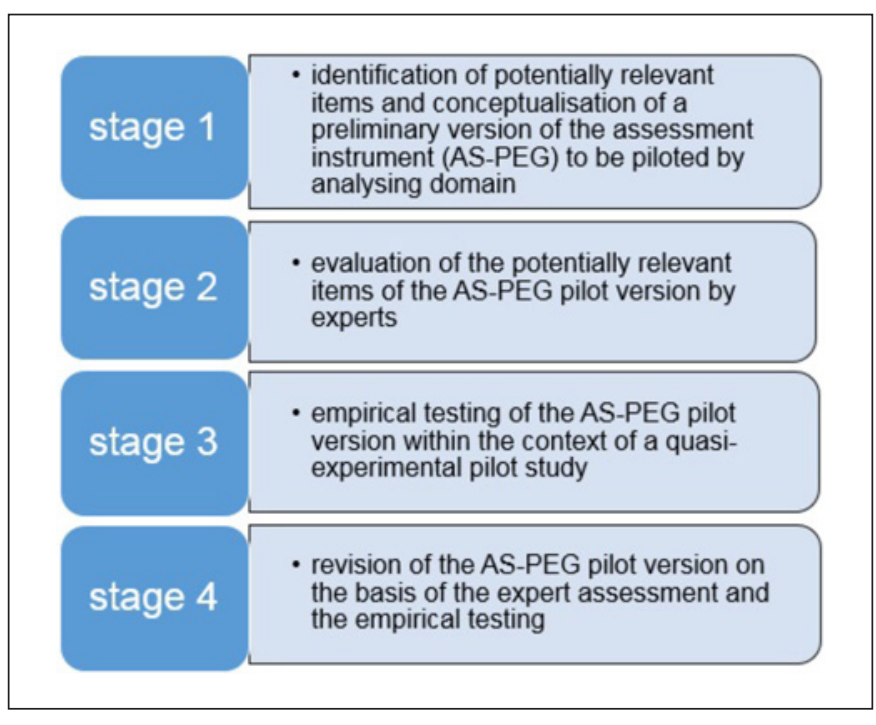

Fig. 1. The stages of development of an assessment instrument for percutaneous endoscopic gastrostomy (AS-PEG).

detailed descriptions of the PEG placement procedure into account, six publications were manually selected and used for the identification of the initial AS-PEG items [23-28].

The primary objective with respect to developing the AS-PEG was to create a score suitable for the assessment of the safety of the puncture of the stomach within the context of PEG placement. Whereas the absence of bleeding and/or infection would suggest the safe completion of the procedure in clinical practice, these indicators were not applicable in this experimental setting. Thus, individual steps of the procedure were operationalized to ensure the assessability of relevant sensorimotor skills.

Stage 2: Judgement Quantification Stage

Content validity of the pilot AS-PEG was scrutinized by an expert panel. In accordance with Grant and Davis [15], the experts' own qualifications and clinical experience were taken into consideration. An expert had to have at least 5 years of clinical experience and be a practitioner performing PEG placement procedures. To ensure anonymity, very few demographic data were recorded (gender, position, title). The experts' written consent to participate in the evaluation was obtained. They received the AS-PEG pilot version, in addition to a cover letter containing all necessary information.

Experts were asked to rate criteria they considered important for a safe puncture of the stomach with respect to the PEG placement on a 4-point Likert scale. Experts also provided an estimate of the time required for the PEG placement procedure. An additional comment field was provided per item, should the experts' want to improve the wording and/or description of the item. Lastly, a comment field was offered for suggestions deemed important by an expert. Anonymization was ensured.

Stage 3: Empirical Testing of the Pilot AS-PEG

An initial evaluation of the pilot AS-PEG was conducted using a quasi-experimental intervention study on simulators. Results were analyzed using quantitative methods. Twenty-four participants ( 7 physicians, 17 nurses) gave informed consent for this pilot study. They received theoretical (sixteen 45-min sessions) and practical training on simulators (eight 45 -min sessions) to prepare them for the PEG placement procedure [18]. 


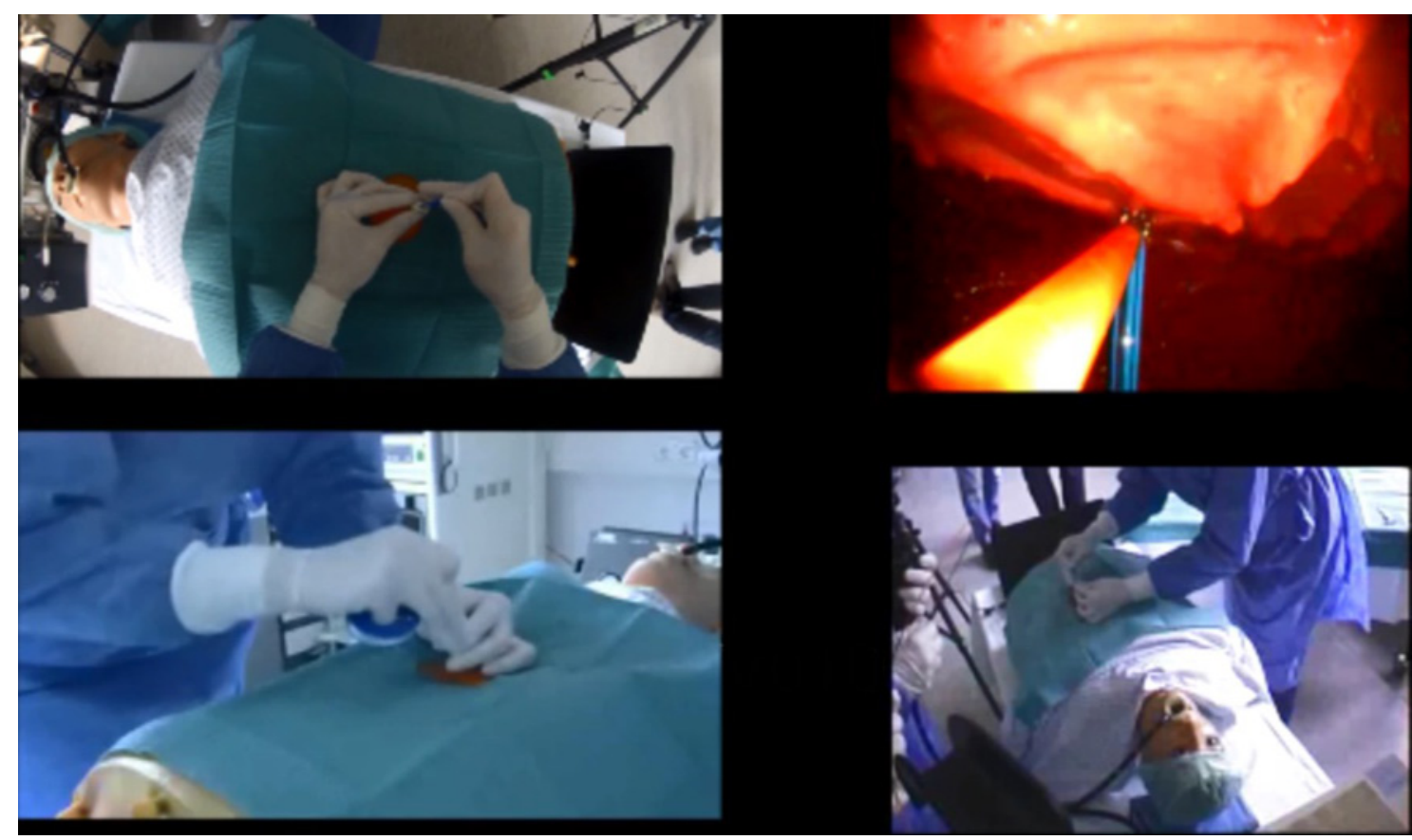

Fig. 2. Video recorded pictures during examination on simulator: upper left: head camera; lower left: room camera right; upper right: endoscopic view; lower right: room camera left.

Trainees then performed the procedure on a new patient-analogous phantom (simulator) for experimental endoscopic surgery. The entire procedure was recorded using three independent cameras focusing exclusively on the hands of the participant to ensure blinding (Fig. 2). Recordings underwent a blinded analysis using the pilot AS-PEG excluding identifiers regarding the participants' age, gender, profession or experience [18].

Stage 4: Revision of the Pilot AS-PEG

The instrument was revised taking the results of the expert evaluation (stage 2) and experiences gathered from the empirical testing (stage 3) into account. In line with Polit and Beck [14], items with an item-content validity index (I-CVI) below 0.78 were discarded and the scale-CVI (S-CVI) recalculated (see below for a detailed description of CVI).

\section{Statistical Analysis}

The analysis of the experts' feedback on the pilot AS-PEG in stage 2 was conducted using IBM SPSS Statistics 22. For the descriptive presentation of the data, median values were reported for individual items.

The CVI [14] was used to corroborate the content validity of the instrument. Content validity is determined based on the extent to which the experts agree that an individual item represents the construct. First, I-CVIs were established. I-CVIs were then used to determine the S-CVI for the pilot AS-PEG, as a whole. For this purpose, Polit and Beck recommend to dichotomize the 4-level Likert scale in order to distinguish relevant from irrelevant items ( 4 and $3=$ relevant $/ 2$ and $1=$ irrelevant).

I-CVIs were determined by the number of experts who rated the item as extremely important (4) or very important (3) and dividing this number by the total number of experts [14]. Individual items should reach values of at least 0.78 , if the corresponding group of experts comprises more than 5 individuals [21].

S-CVIs were established by dividing the total number of fields filled in with " 3 " or " 4 " $(n=290)$ by the total number of expert rat- ings $(n=477)$. Polit and Beck state that S-CVIs should reach at least 0.80 [14].

The blinded analysis of the video material (stage 3) was performed using the pilot AS-PEG [18]. Dichotomous categories ("yes, implemented correctly"/"no, not implemented correctly") were used to analyze the participants' actions with the help of the 44 items. One point was awarded if an item was implemented correctly; otherwise, no points were given.

This results in a maximum of 42 points that could be achieved, since two items ( 3 and 4 ) were unratable within the context of this study due to the specific laboratory setting.

\section{Results}

The pilot AS-PEG developed during stage 1 encompassed 13 categories with a total of 44 items. The expert panel (stage 2) consisted of 11 clinical physicians from Germany (10 gastroenterologists, 1 visceral surgeon). Actual participation of the panel amounted to $100 \%$ with respect to content validation of the pilot AS-PEG.

On average, the experts considered 30 of the 44 initial items (68\%) to be extremely important (4) or very important (3) for the safe puncture of the stomach within the context of PEG placement; and I-CVIs ranged between 0.55 and 1.00. Experts unanimously considered three items (number 7, 20 and 30) extremely important for a safe stomach puncture and subsequent tube placement (I-CVI: 1.00). The I-CVIs of the additional 11 items, scored either with a 4 or 3 , ranged from 0.80 to 0.91 (Fig. 3). 


\begin{tabular}{|c|c|c|c|c|c|c|}
\hline \multirow[t]{2}{*}{ Category } & \multirow{2}{*}{$\begin{array}{l}\text { Previ } \\
\text { ous } \\
\text { Item } \\
\text { № }\end{array}$} & \multirow{2}{*}{$\begin{array}{l}\text { Operationalizing criteria for the safe puncture of the stomach within the } \\
\text { context of the PEG placement procedure } \\
\text { (expected skills) }\end{array}$} & & & & \multirow[b]{2}{*}{ comment } \\
\hline & & & $1-\mathrm{CVI}$ & $\begin{array}{c}\text { Yes, } \\
\text { correct } \\
\text { done }\end{array}$ & $\begin{array}{l}\text { No, } \\
\text { not correct } \\
\text { done }\end{array}$ & \\
\hline $\begin{array}{l}\text { Preparation of the } \\
\text { hands }\end{array}$ & 1 & $\begin{array}{l}\text { Hygienic hand antisepsis: Hands are disinfected with an antiseptic, leaving no areas } \\
\text { untreated, in accordance with DIN EN ISO } 1500 \text {. }\end{array}$ & 0.91 & & & \\
\hline \multirow{3}{*}{$\begin{array}{l}\text { Preparation of the } \\
\text { sterile instrument } \\
\text { table }\end{array}$} & 3 & The instrument table is prepared under sterile conditions. & 0.91 & & & \\
\hline & 4 & Hands remain above the waistline and only touch the objects handed to the trainee. & 0.91 & & & \\
\hline & 5 & $\begin{array}{l}\text { Sterile instruments are seized and placed on the table in a suitable order (from left to } \\
\text { right), always maintaining the sterile field. }\end{array}$ & 0.82 & & & \\
\hline \multirow[t]{2}{*}{ Diaphanoscopy } & 7 & $\begin{array}{l}\text { Examination of the puncture site: If pressure is applied to the anterior stomach wall } \\
\text { (with a finger or the cannula sheath), the palpation of this part of the abdominal wall } \\
\text { becomes visible in the endoscopic image. }\end{array}$ & 1 & & & \\
\hline & 8 & The trainee performing the puncture controls this on the monitor. & 0.91 & & & \\
\hline $\begin{array}{l}\text { Disinfection of the } \\
\text { puncture site }\end{array}$ & 10 & $\begin{array}{l}\text { The area on the abdomen is disinfected with circular movements, outwards from the } \\
\text { puncture site. }\end{array}$ & 0.91 & & & \\
\hline Sterile draping & 12 & $\begin{array}{l}\text { In a movement away from the body of the trainee performing the procedure, the } \\
\text { puncture site is covered with fenestrated surgical drape. }\end{array}$ & 0.82 & & & \\
\hline Local anaesthesia & 14 & $\begin{array}{l}\text { The needle then pierces the stomach through the layers of the abdominal wall. It is } \\
\text { clearly visible in the endoscopic image. }\end{array}$ & 0.91 & & & \\
\hline \multirow[t]{3}{*}{$\begin{array}{l}\text { Insertion of the } \\
\text { puncture cannula }\end{array}$} & 19 & $\begin{array}{l}\text { The puncture cannula is inserted in the same direction and plane as the injection } \\
\text { needle. }\end{array}$ & 0.8 & & & \\
\hline & 20 & The free end of the puncture cannula with stylet is visible within the gastric lumen. & 1 & & & \\
\hline & 22 & $\begin{array}{l}\text { The steel stylet is removed from the puncture cannula (trocar tube) held in place with } \\
\text { hands. }\end{array}$ & 0.82 & & & \\
\hline \multirow[t]{2}{*}{$\begin{array}{l}\text { Moving the } \\
\text { guidewire }\end{array}$} & 26 & $\begin{array}{l}\text { To avoid dislocation, the puncture cannula (trocar tube) is held in one hand resting } \\
\text { on the abdomen during the whole procedure. }\end{array}$ & 0.82 & & & \\
\hline & 30 & $\begin{array}{l}\text { Once resistance is encountered, the tapered end of the PEG tube has reached the } \\
\text { puncture cannula and both are drawn out of the abdomen along the wire, while } \\
\text { counter-pressure is applied on the abdomen until the internal retention plate has } \\
\text { been secured (to avoid a pneumoperitoneum). }\end{array}$ & 1 & & & \\
\hline Total time required & \multicolumn{2}{|r|}{ Number in minutes } & & & & \\
\hline
\end{tabular}

Fig. 3. Revised ASsessment instrument for Percutaneous Endoscopic Gastrostomy AS-PEG for the evaluation of the PEG placement procedure. The figure shows revised items to be used in the new version of the AS-PEG following the elimination of items with an I-CVI under 0.78 .

The 14 items (32\%) that were rated as important (2) or less important (1) included steps pertaining to the aftercare once the tube was placed. I-CVIs ranged from 0.00 to 0.45 . For the initial instrument, the S-CVI was calculated as the average of all I-CVIs and was 0.61 for the pilot AS-PEG. On average, the experts set the estimated duration of the whole procedure at 10-30 min with a mean of 19 min ( $\mathrm{SD}=7 \mathrm{~min}$ ).

Four experts suggested additional items including: exclusion of previous high-dose proton pump inhibitor administration and/or systemic anticoagulation treatment, pre-endoscopic administration of antibiotics, oral hygiene, and postoperative loosening of the PEG placement cannula after $24 \mathrm{~h}$ by qualified staff.

Five experts did not return anonymous answers, but rather wrote letters with explanations. These letters contained the following comments: the instrument seems artificial and consists of very small steps; hygiene is essential; training on simulators cannot reproduce failed punctures; and the injection needle for the local anesthetic should not remain in place.

During stage 3, the pilot AS-PEG was used to assess the recorded video sequences of the 24 participants (male: $n=4$, female: $n=20$ ) training on simulators. In total, 42 items were assessed. Correct implementation was achieved in $75-100 \%$ of all cases for 37 out of 42 items. The five remaining items were executed correctly in 50$74 \%$ of all cases. The average score for the 42 assessed items was $32-40$ points ( mean $=37 ; \mathrm{SD}=2$ ). The average time required for the PEG placement procedure was 5: 59-13:38 $\mathrm{min}($ mean $=8: 25 \mathrm{~min} ; \mathrm{SD}=1: 43 \mathrm{~min})$.

Results from stage 2 and stage 3 were used to revise the pilot AS-PEG in stage 4. Fourteen items remained after removing an item with an I-CVI below 0.78 (Fig. 3). The recalculated S-CVI was 0.90 (range 0.8-1.0).

Item 20 ("The free end of the cannula is visible within the gastric lumen") was ultimately rephrased to "The free end of the puncture cannula with stylet is visible within the gastric lumen" (Fig. 3). This was necessary, as upon video review, the blunt puncture cannula had been introduced into the stomach, i.e., without the stylet, in one case.

\section{Discussion}

This study developed an ASsessment instrument for monitoring the sensorimotor skills required for $\underline{P E G}$ placement (AS-PEG). A quasi-experimental intervention study on simulators was conducted with the focus of training physicians' and nurses' sensorimotor skills required for the puncture of the stomach within the context of PEG placement. The revised instruments' content validity with 14 items demonstrated to have good content validity.

Sensorimotor skill acquirement and subsequent assessment play an integral role in the professional develop- 
ment of physicians and nurses. The development of this instrument encompassed several stages. The reviewed literature contained detailed descriptions of the PEG placement procedure. A comparison of the respective steps facilitated the elaboration of an initial version of the instrument. Since the study focused on the puncture of the stomach using the pull PEG technique, only this part of the procedure was described.

The outcome of the assessment suggests that the required sensorimotor skills were well represented in the pilot AS-PEG version. Furthermore, Lynn (1986), Polit and Beck (2006) specify that I-CVIs of a valid instrument should reach I-CVIs of 0.80 for four or five experts and 0.78 for nine experts $[14,21]$. In this study, 11 experts assessed content validity of the items of the initial AS-PEG version. Thirty I-CVIs of the pilot AS-PEG instrument did not reach 0.78 and the S-CVI was only 0.61 , suggesting that the first version required improvement. The expert invitation letter included an opening question that conceivably could have implied the puncture step to be the only extremely or very important step in terms of safety. This could have then resulted in excessively low values for all of the items pertaining, for instance, to aftercare.

Criticism regarding breaking down the procedure into very small steps and the artificial appearance of the instrument were noted (Items 27, 31, 36-40; I-CVIs 0.00$0.44)$. However, they represent indispensable actions and without these steps, the PEG placement procedure could not continue. Moreover, the very detailed description was essential to analyze all sensorimotor skills necessary in this pilot study for a safe PEG placement [18].

Item 44 (endoscopic control reveals that the internal retention plate is located on the stomach wall and has been secured with sufficient freedom of movement; avoiding excessive traction) reported a median value of 1 and an I-CVI of 0.27. Nevertheless, whether trainees unfamiliar with the procedure could benefit from endoscopic control during the training stage remains a matter of debate. To this point, it serves to examine how firmly or loosely the tube is secured. For this purpose, the image displayed on the monitor would be indispensable. If the instrument is used in combination with simulators, there is no reasonable objection. However, in a clinical setting, during a patient examination, endoscopic control would constitute an additional risk for the patient and would therefore only be appropriate in case of doubt [27, 29].

With respect to the development of new instruments, Grant and Davis [15] underscore the significance of consulting experts who can judge content, comprehensive description, and clear definition of the items. For this study, physicians were consulted, as they represent the only profession allowed to perform the procedure in Germany under current law. Nurses are responsible for the preparation of patients and instruments and for the aftercare including the dressing of the tube $[24,26]$. The low I-CVIs reached in the areas of aftercare and dressing might be due to the fact that physicians are rarely involved in these steps.

In total, the expert survey had only seven missing values. In contrast, the experts provided specific recommendations that proved to be useful for the elaboration of the revised version of the instrument, for example, "good hygienic preparation." According to Lynn [21], such complementary input constitutes a significant means of avoiding the possible omission of areas.

Seven physicians and 17 nurses participated in stage 3 , resulting perhaps in an imbalance. However, due to the fact that this training curriculum was provided to physicians and nurses as a multi-professional education for the first time, there seems to be a greater interest for nurses, likely explaining the aforementioned participant imbalance. In contrast, physicians routinely learn the procedure in the clinical setting and/or through courses given by the German Society of Digestive and Metabolic Disease [30].

Video material was analyzed with the pilot AS-PEG. De Vet et al. [17] recommend instrument field-testing during development, in order to facilitate redesign where appropriate. As in the present case, this stage is ideally conducted prior to clinical application. The individual items facilitate the step-by-step assessment of the procedure as well as training since the activities can be divided into sequences.

The literature used for the development of the instrument [23-28] proved to be adequate as it contained detailed descriptions of the PEG placement procedure. The very small steps, criticized by some experts, were crucial for the practical testing and necessary to ascertain whether the trainees had reached the learning objective of safely performing the puncture of the stomach.

Rephrasing item 20 became necessary after the analysis of video material. A blunt puncture was discovered due to the inappropriate handling of the cannula. The significance of the correct handling arises from the fact that in a real examination, a blunt puncture could constitute a risk to patient safety, for example bleeding. The risk of bleeding amounts to less than $0.01-0.9 \%$ in these examinations [29, 31].

After the elimination of items with I-CVIs below 0.78 , 14 items remained, all with content validity values between 0.80 and 1.00 . These remaining items can be identified as the parameters or anchor points within the sequence of events that facilitate the assessment of sensorimotor skills.

The subsequent recalculated S-CVI amounted to 0.90 , an appropriate result with respect to the content validity of the AS-PEG instrument. Due to the reduction to 14 es- 
sential elements, the revision has rendered the AS-PEG an instrument whose feasibility can be determined.

In practice, a physician's ability to perform endoscopic examinations correctly is commonly determined by the number of procedures completed during specialty training [3]. Furthermore, medical school curricula distinguish between medical knowledge, medical skills and practical expertise, and professional demeanor [32, 33]. In nursing curricula, three categories of learning objectives were identified: knowledge (cognition), skills (sensorimotor) and attitudes (affectivity) [2].

The curriculum used for this quasi-experimental intervention study on simulators defined learning objectives for both the theoretical and practical training components. Training on simulators can aid medical and nursing staff in acquiring pertinent sensorimotor skills. Thus, simulated training helps to ensure future safe punctures of the stomach when performing a PEG in clinical setting.

\section{Limitations}

Only physicians were invited to provide input for the development of the assessment instrument due to current German law. However, it could have skewed the results, as nurses might have rated the steps pertaining to the aftercare as extremely or very important for the safety of the procedure.

With respect to the criteria for the selection of the experts, no threshold number of PEG placement procedures performed per physician per year was defined as eligibility to become experts. Moreover, the study did not specify whether an expert's 5 years of experience referred to PEG placement procedures or rather to his/her practical experience as gastroenterologists. These details might have been significant, as the number of procedures performed by an expert and his/her experience over longer periods could have been used to further substantiate the person's aptitude for assessing these procedures.

Real examinations on patients can entail further requirements due to a patient's movements, bleeding or unexpected anatomical anomalies. A trainee's reaction to such scenarios cannot be assessed with the developed instrument. A further category concerning the general impression of his/her professional demeanor during the examination could address the above; however, further validation would be required.

\section{Conclusion}

The development of the AS-PEG is based on a systematic literature review and a standardized evaluation by renowned experts. Following a pilot study and subsequent instrument redesign, the revised version of the instru-

ment with 14 items demonstrates a good content validity. Ultimately, the AS-PEG facilitates the assessment of the required sensorimotor skills to successfully perform stomach punctures for PEG placement procedures across institutions and professions without respect to the number of procedures previously performed. Next steps include validation of the revised AS-PEG in a clinical setting. Further instrument enhancement with the aim of including the aforementioned categories, such as depth perception, ambidexterity, efficiency and independence, will also be considered.

\section{Acknowledgments}

We would like to thank the experts for sharing their experience and knowledge for this study. We thank the physicians and nurses of the intervention study for their participation.

\section{Statement of Ethics}

The study was conducted in accordance with the principles of the Declaration of Helsinki and obtained approval of the responsible institutional review board (IRB, No. 162/2014).

\section{Conflict of Interest Statement}

The authors have no conflicts of interest to declare.

\section{Funding Sources}

There have been no funding sources.

\section{Author Contributions}

We confirm that each person designated as author qualifies for authorship. The participation level of each author was as follows: Monika Engelke and Christiane Kugler: study design, study and data coordination, drafting the manuscript. Karl-Ernst Grund: support with study design, sufficient revision of the manuscript. Dieter Schilling: support with study design, sufficient revision of the manuscript. Ulrike Beilenhoff: study design, sufficient revision of the manuscript. Ferdinand Stebner: statistical and data administration support, data analyses, sufficient revision of the manuscript.

References

Visc Med 2021;37:212-218

DOI: $10.1159 / 000511350$
1 MFT Medizinischer Fakultätentag der Bundesrepublik Deutschland e. V. Nationaler Kompetenzbasierter Lernzielkatalog Medizin (NKLM); 2015. Available from: http://www. nklm.de/files/nklm_final_2015-07-03.pdf

2 DKG. DKG-Empfehlung zur pflegerischen Weiterbildung vom 29.09.2015, http://www. dkgev.de/media/file/22128.DKG-Empfehlung_Weiterbildung_Pflege.pdf 
3 Vilstrup H, Jeppesen P, Nyenberg D, et al. The blue book. Speciality Training Programme and Curriculum for Gastroenterology and Hepatology; 2017. Available from: http:// www.eubogh.org/blue-book/

4 Faulx AL, Lightdale JR, Acosta RD, Agrawal $\mathrm{D}$, Bruining $\mathrm{DH}$, Chandrasekhara $\mathrm{V}$, et al.; ASGE Standards of Practice Committee. Guidelines for privileging, credentialing, and proctoring to perform GI endoscopy. Gastrointest Endosc. 2017 Feb;85(2):273-81.

5 Sedlack RE. The Mayo Colonoscopy Skills Assessment Tool: validation of a unique instrument to assess colonoscopy skills in trainees. Gastrointest Endosc. 2010 Dec;72(6):112533.

6 Götzberger M, Rösch T, Geisenhof S, Gülberg V, Schmitt W, Niemann G, et al. Effectiveness of a novel endoscopy training concept. Endoscopy. 2011 Sep;43(9):802-7.

7 Beyer A, Dreier A, Kirschner S, et al. Objective Structured Clinical Examination (OSCE) als kompetenzorientiertes Prüfungsinstrument in der pflegerischen Erstausbildung: eine Literaturanalyse $\mathrm{zu}$ ihrer internationalen Anwendung. Pflegewissenschaft. 2016;29:193203.

8 Walsh CM, Sherlock ME, Ling SC, Carnahan $\mathrm{H}$. Virtual reality simulation training for health professions trainees in gastrointestinal endoscopy. Cochrane Database Syst Rev. 2012 Jun;(6):CD008237.

9 Haycock AV, Youd P, Bassett P, Saunders BP, Tekkis P, Thomas-Gibson S. Simulator training improves practical skills in therapeutic GI endoscopy: results from a randomized, blinded, controlled study. Gastrointest Endosc. 2009 Nov;70(5):835-45.

10 McKinley RK, Strand J, Gray T, Schuwirth L, Alun-Jones T, Miller H. Development of a tool to support holistic generic assessment of clinical procedure skills. Med Educ. 2008 Jun; 42(6):619-27.

11 Koch AD. Teaching Colonoscopy - from Novice to Competence: Colonoscopie - van kennis gestuurd naar competentie gericht onderwijs. Rotterdam: Erasmus University Rotterdam; 2014
12 Ekkelenkamp VE, Koch AD, de Man RA, Kuipers EJ. Training and competence assessment in GI endoscopy: a systematic review. Gut. 2016 Apr;65(4):607-15.

13 Downing SM. Validity: on meaningful interpretation of assessment data. Med Educ. 2003 Sep;37(9):830-7.

14 Polit DF, Beck CT. The content validity index: are you sure you know what's being reported? Critique and recommendations. Res Nurs Health. 2006 Oct;29(5):489-97.

15 Grant JS, Davis LL. Selection and use of content experts for instrument development. Res Nurs Health. 1997 Jun;20(3):269-74.

16 Aggarwal R, Grantcharov TP, Darzi A. Framework for systematic training and assessment of technical skills. J Am Coll Surg. 2007 Apr;204(4):697-705.

17 de Vet. Henrica C. W., Terwee CB, Mokkink LB et al. Measurement in medicine: A practical guide. Cambridge, New York: Cambridge University Press; 2011.

18 Engelke M, Grund KE, Schilling D, Beilenhoff U, Kern-Waechter E, Engelke O, et al. Vergleich der Sicherheit der perkutan gastralen Punktion im Rahmen der PEG-Anlage zwischen Ärzten und spezialisierten Pflegenden - eine nicht randomisierte, interventionelle Pilotstudie an Simulatoren. Z Gastroenterol. 2018 Mar;56(3):239-48.

19 Waltz CF, Strickland O, Lenz ER. Measurement in nursing and health research. New York (NY): Springer Publishing Company; 2005.

20 Streiner DL, Kottner J. Recommendations for reporting the results of studies of instrument and scale development and testing. J Adv Nurs. 2014 Sep;70(9):1970-9.

21 Lynn MR. Determination and quantification of content validity. Nurs Res. 1986 Nov-Dec; 35(6):382-5

22 Gauderer MW, Ponsky JL, Izant RJ Jr. Gastrostomy without laparotomy: a percutaneous endoscopic technique. J Pediatr Surg. 1980 Dec;15(6):872-5.

23 Dormann AJ. Künstliche enterale Ernährung. In: Löser C, ed. Unter- und Mangelernährung: Klinik, moderne Therapiestrategien, Budgetrelevanz; 81 Tabellen. Stuttgart [u.a.]: Thieme; 2011. pp. 122-30.
24 Grund K, Königsrainer I, Zipfel A. Endoskopisch gelegte Ernährungssonden: Technische Tipps und Tricks. Endosk Heute. 2006; 19(2):98-105

25 Grund KE, Zipfel A. Permanente Sonden. In: Kahl S, Kähler G, Dormann A, eds. Interventionelle Endoskopie: Lehrbuch und Atlas. Munich: Urban \& Fischer; 2006. pp. 355-79.

26 Jopke F, Besser C. PEG und assoziierte Verfahren. In: Gottschalk U, ed. Thiemes Endoskopieassistenz: 47 Tabellen [mit 20 Filmen auf DVD]. Stuttgart, New York, NY: Thieme; 2009. pp. $167-86$

27 Löser C, Aschl G, Hébuterne X, Mathus-Vliegen EM, Muscaritoli M, Niv Y, et al. ESPEN guidelines on artificial enteral nutritionpercutaneous endoscopic gastrostomy (PEG). Clin Nutr. 2005 Oct;24(5):848-61.

28 NZNO. New Zealand Nurses Organization (INC) Recommendations for: registered nurse first assist for the placement of percutaneous endoscopic gastronomy tubes in endoscopy suites in New Zealand: Endoscopy service policy guidelines. Wellington, N.Z. New Zealand Nurses Organization; 2010.

29 Dormann A. Endoskopische Ernährungstechniken. In: Kähler G, Götz M, Senninger N, editors. Therapeutische Endoskopie im Gastrointestinaltrakt. Berlin: Springer; 2016. pp 139-75.

30 Faiss S, Schmitt W. Endoskopische Trainingskurse nach den Kriterien der DGVS. Modul 1 Grundlagen der Endoskopie und diagnostische ÖGD; 2018. Available from: https://www.dgvs. de/wp-content/uploads/2016/11/Kursmodul_1.1_Grundlagen_Endoskopie_u_diagn_ OEGD.pdf. Accessed: September 30, 2018.

31 Peveling-Oberhag J, Osman I, Walter D, Filmann N, Stratmann K, Hausmann J, et al. Risk factors for early and late procedure-related adverse events in percutaneous endoscopic gastrostomy: A single center, retrospective study. J Gastroenterol Hepatol. 2019 Feb; 34(2):404-9.

32 Medizinische Fakultät der Christian-Albrechts-Universität zu Kiel, ed. Lernzielkatalog Medizin. Zweiter Studienabschnitt; 2011.

33 Korzilius H. (Muster-) Weiterbildungsordnung - Novelle einstimmig beschlossen. Dtsch Arztebl. 2018;115:A970-3. 